\title{
Evaluation of rock mechanical properties via scratch testing and its impact on energy production: comprehensive review
}

\author{
Oladoyin Kolawole*, and Ion Ispas
}

Bob L. Herd Department of Petroleum Engineering, Texas Tech University, Lubbock, TX 79409, USA

\begin{abstract}
The scratch test is a non-destructive method made up of pushing a tool across the surface of a weaker rock at a given penetration depth. The uniaxial rock strength (UCS), fracture toughness (KIC), and other geomechanical parameters influences how fracture nucleates, but fracture sizes and geometry adopted in hydraulic fracture design and modeling are most often overestimated. Although several researchers have attempted to evaluate UCS, $\mathrm{K}_{\mathrm{IC}}$ and other geomechanical properties in conventional and unconventional formations through scratch testing method, but there remain differing opinions on the fundamental approach and principles to be adopted in estimating those properties. Therefore, the evaluation of geomechanical parameters and their effect on hydrocarbon exploration, energy storage, and hydrocarbon exploitation remain an important issue for energy industry. In this paper, we present a comprehensive review of the methods of approach, applications, and the mechanics of rock scratching. We show the merits of scratch test over other methods of estimating rock mechanical properties. Our review focuses on over 50 previous experimental studies using scratch tests in the past few decades to investigate UCS, KIC and other geomechanical properties, including their impact on rock failure, fracture initiation and propagation. Finally, we highlight the fundamental research questions that are yet to be addressed. We envisage that advancement in our knowledge will improve optimization of hydrocarbon exploitation, energy storage, and field-scale modeling for energy production operations.
\end{abstract}

\section{Introduction}

The scratch test is a quasi-non-destructive method made up of pushing a tool across the surface of a weaker rock and tracing the groove at a given penetration depth. The uniaxial rock strength (UCS) which is the ultimate stress a rock can withstand before undergoing failure, is characterized by rock confining pressure, stress-strain relationship, and pore-fluid pressure. Analysis and prediction of the insitu rock failure behavior as a function of rock type, pore pressure, spatio-temporal stresses, and faultreactivation potential provides critical information for proactive decision-making to achieve successful energy production operations. In the optimization of hydrocarbon exploitation, hydraulic fracturing has proven to be one of the most efficient methods [1, 2]. During this treatment, complex fracture networks are often generated, and the interaction of hydraulic and natural fractures significantly influences the complexity of the fracture networks created [3, 4]. Stronger rocks will exhibit greater fracture toughness $\left(K_{I C}\right)$, which will influence the fracture geometry and propagation. UCS, $K_{I C}$, and other rock mechanical parameters influencing how the fracture nucleates [5], fracture size and geometry, but fracture sizes and geometry adopted in hydraulic fracture design and modelling, Discrete Fracture Network (DFN) modeling, and Finite Element Modeling (FEM); are most often overestimated. Although scratch tests are applicable nowadays to several fields of science and engineering, ranging from strength characterization of rocks and cements/ceramics $[6,7,8,9,10,11,12]$, to damage of polymers $[13,14,15,16,17,18,19,20$, $21]$ and metals $[22,23,24,25]$, and quality control of thin films and coatings $[16,19]$; the underlying rock failure mechanisms, characterization, and applications has not been fully explored. Although several researchers have attempted to evaluate and quantify UCS, fracture toughness, and other rock

\footnotetext{
*Corresponding author: doyin.kolawole@ttu.edu
} 
mechanical properties in conventional and unconventional reservoir rocks using indentation and scratch testing methods, but there remain differing opinions on the fundamental approach and principles to be adopted in estimating those parameters.

In this paper, we discussed and summarized the key findings regarding the use of scratch testing method to estimate rock strength and other geomechanical properties over the past few decades. We extensively discussed the methodology, modifications, and applications of scratch test approach and devices published research studies. We highlighted the advantages of scratch testing method over other conventional methods of estimating geomechanical properties. We further provided recommendations for future research to address the identified outstanding problems related the use of scratch test method to estimate geomechanical properties for improved hydrocarbon exploitation and production.

\section{The Scratch Test Method}

\subsection{Scratch Test Method Vs Other Methods}

The uniaxial compressive test using load frame to evaluate the UCS of core plugs is one of the most popular methods. The indentation test method is another popular conventional method of estimating mechanical properties of rocks [26], and other materials. This method involves the use of a scratching tool to create indentations on the surface of the material surface. In a research study [27], micro-nano indentation method was utilized to evaluate and predict $K_{I C}$ in shale rocks, but the study failed to account for maximum holding stage on the indentation-displacement curves in fracture toughness estimation. This fracture toughness model deficiency was highlighted and corrected in [28], but the final $K_{I C}$ values are in the order of magnitude two. The macroscopic and mesoscopic rock mechanical parameters of shale rocks were investigated by authors in [29] using microindentation test method. The shale outcrops from the Cambrian Longmaxi formation in Sichuan Basin, China, was utilized for the study. In the results, the authors observed that mesoscopic elastic modulus and indentation hardness are heterogeneously distributed across the formation and exhibits a nonlinear increase behavior with rise in packing density. The microscopic mechanical properties of shale rocks were not accounted for in this study. The shale rock samples from the Longmaxi formation in Sichuan Basin, China, was utilized to estimate $K_{I C}$ through micro-indentation method [30]. The authors aim to address the previous limitation of the $K_{I C}$ estimation in [28], and their results showed much lower $K_{I C}$ values. In $K_{I C}$ measurement using indentation method, results are more of qualitative, and can yield high inaccuracy and subjectivity by virtue of the crack length measurement requiring optical imaging method, which is onerous task for non-translucent rocks like shale [31]. Other method of estimating rock's UCS are the point-load test $[32,33]$. The "Drill Test" [34] was developed using the drilling concept and incorporates $2 / 3$ butt core sections to evaluate UCS in shale rocks.

The rebound hardness test method using Equotip $^{\mathrm{R}}$ hardness tester $[35,36]$ was initially adopted for evaluating the UCS of rocks, but recently utilized for creating UCS logs and strength contrast profiles of shale rocks $[37,38]$. The rebound hardness test can also be carried out using Schmidt hammer [39]. Although the rebound index test is also useful in qualitatively estimating the UCS of rocks, it has proven inefficient in providing a continuous and accurate quantitative rock strength profile [40]. This is another means the scratch test has proven its efficiency over other methods of testing rock strength by providing continuous high-resolution logs of rock strength with high degree of repeatability. The effect of anisotropy in $K_{I C}$ was estimated in [41] using Chevron Bend (CB) test and Boundary Element Method model. The authors in [42] also utilized the Chevron Notched Semicircular Bend (CNSCB) test to estimate rock strength and fracture toughness of Woodford shale rocks, with the estimated fracture toughness $\left(K_{I C}\right)$ values in Lower and Middle Woodford shale much lesser than values of Upper Woodford shale. In study [43] using a modified Short-Rod sample geometry to estimate anisotropic $K_{I C}$ values of Mancos Shale rock, conflicting values were obtained in divider, short-transverse, and arrester configurations. Coring operation was also suggested [44] as another viable method of estimating UCS from data obtained from acoustic and bulk density logs.

The advantages of scratch test method over other conventional methods discussed to estimate rock strength and other geomechanical properties are that $[45,46,47,48,49,50,51]$ :

a. It is quasi non-destructive, and the post-test core samples remain intact which can be utilized for other destructive or non-destructive tests.

b. It provides direct equivalent measurement with the rock's UCS.

c. It requires limited and minimal level of sample preparation.

d. It is simple, quick, and highly repeatable.

e. It can be conducted on any dimension of rock, as the results are not affected by the core sample geometry. 
f. It provides precise continuous profile of rock strength over the scratch interval.

The scratch profile from the scratch tests provides a reliable quantitative measurement of the scale and distribution of the heterogenous properties along the tested core samples.

\subsection{The Mechanics of Rock Scratching}

In the scratch testing method, continuous trace of the groove of the rock surface is conducted with a stronger cutting tool, while the cutter penetration depth $(d)$ and the velocity $(v)$ between the cutter and the rock are held constant. The horizontal force $\left(F_{T}\right)$ is parallel to the cutter velocity, and the vertical force $\left(F_{V}\right)$ which is normal to the cutter velocity; are measured. The rock cutting configuration is also characterized other parameters such as: the back-rake angle $(\theta)$; the cutter/probe geometry; the contact surface between the cutter and the rock surface which is represented by $l$; the friction coefficient $(\mu)$ beneath the wear flat of the cutter. The mechanisms of rock scratching are evident in the linear relationship between cutter penetration depth $(d)$ and $F_{T}$. The two rock failure mechanisms depending on the cutter penetration depths are $[46,52]$ :

a. Ductile failure mode: Also known as "plastic flow". The ductile failure mode occurring at shallow penetration depth $(d)$, is characterized by the rock shearing ahead of the cutter. As the rock matrix and the grains are dislodged, the rock grains and powder accumulate continuously ahead of the cutter, and they are removed by the moving cutter.

b. Brittle failure mode also known as "chipping", The brittle failure mode occurring at large penetration depth $(d)$, is characterized by macroscopic fractures generating from the tip of the cutting tool and propagates upwards towards the rock surface ahead of the cutter. The chips and fragments formed are removed by the cutter. [Break]

The brittle failure mode is dependent on fracture toughness $\left(K_{I C}\right)$, the ductile failure mode on UCS, and the transition between ductile and brittle failure modes is dependent on the cutter penetration depth (d). Researchers [53] adopted the Bažant's Size Effect Law (SEL) to investigate the critical ductileto-brittle transition depth in a wide range rock type. This critical ductile-to-brittle transition penetration depth $\left(d_{c}\right)$, distinguishes the ductile failure regime from the brittle failure regime. The Quasi-brittle fracture property of cement paste was investigated by [5] to account for the linear elastic relationship between applied forces and scratch width and depth $(w \sqrt{d})$. The authors proposed a linear scaling method from scratch geometrical scale to large scale ranges for estimating $K_{I C}$ in homogenous materials.

\subsection{Scratch Test Devices}

\subsubsection{The Rock Strength Device}

The Rock Strength Device (RSD) [45, 46, 47, 49, 54, $55,56,57,58]$ is designed to scratch the rock surface while the normal and tangential forces applied to the cutter are measured, and the device is kinematically controlled. The main components of the RSD are: 1 a transverse with a core holder of length $l ; 2-$ a moving cart; 3 - housing the vertical positioning system; 4 - the load cell; 5 - cutting tool; 6 computer controlled stepper-motor (controls the horizontal movement of the cart); 7 - horizontal ball screw; 8 - gearbox; 9 - the vertical positioning system (controls the depth of cut); 10 - micrometer; 11 - locking system (keeping the vertical mechanical system locked against the frame to maintain a constant penetration depth). The load sensor measures tangential $\left(F_{T}\right)$ and vertical $\left(F_{V}\right)$ forces acting on the cutter.

\subsubsection{The Wombat Machine}

The wombat scratch test machine [50, 51, 59] as shown in Fig. 1, is a unique scratch test equipment developed by Epslog S.A. with the capability of testing core samples up to $3 \mathrm{ft}$ long and a diameter range of $0.5 \mathrm{in}$. to $6 \mathrm{in}$. The following are the main components of the Wombat machine: horizontal bed on which the core samples are fixed; mobile carriage to hoist the vertically erected cutter; load sensor measuring $F_{T}$ and $F_{V}$; high-definition camera to capture continuous images of the rock core surface during scratching. The results are processed and analyzed by a computer software solution.

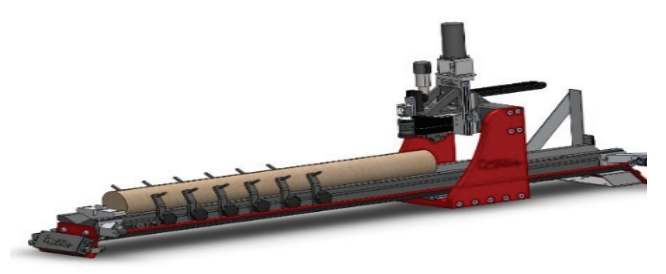

Figure 1: Wombat scratch machine (Image courtesy of Epslog S.A.[59])

\subsubsection{Others}

The Mechanical Profiler Test System (MPTS) from TerraTek $\operatorname{TSI}^{\mathrm{TM}}[60,61,62]$ is another type of scratch test equipment utilized for estimating rock 
mechanical properties and other parameters through the scratch testing method. Its system consists of a moving cart containing a core sample holder, a cutting tool with the rock "scratching" capability, loading cell to measure the vertical and horizontal forces acting on the rock surface. As part of an existing compression machine, a simple scratching cell was developed [63] and utilized to create rock strength correlation for predicting UCS of rocks in Saudi Arabia. Most recently, the miniature linear cutting device [64] was developed using a milling machine and designing it to measure forces and distance scratched by the probe.

\section{Estimation of Rock Mechanical Properties using Scratch Test Approach}

\subsection{Uniaxial Compressive Strength (UCS)}

The scratch test can be resourceful in estimating reservoir geomechanical and petrophysical properties. The concept of obtaining rock strength information from rock cutting tests was proposed [54], and this approach was dependent on phenomeno-logical model of continuously cutting of rock with blunt cutter. This cutter/rock interaction model in ductile failure mode was developed based on three assumptions, irrespective of the cutting tool wear. These assumptions are that $[54,65]$ : (i) the forces acting on the cutter face, averaged over a distance higher than the penetration depth, is directly proportional to the cross-sectional area $\left(A_{c}\right)$ due to horizontal force; (ii) the inclination of the average force acting normal to the cutter face is constant; (iii) friction force at the wear-flat rock interface exists. The above developed model is composed of three major parameters:

a. the intrinsic specific energy $(\varepsilon)$ applicable to the rock cutting process;

b. the inclination $(\zeta)$ of the average force acting on the face of the cutter;

c. the coefficient of friction $(\mu)$ on the wear flat/rock interface.

The model assumptions and its application to estimate rock strength is summarized in Eqns. 1-6 as:

$$
\begin{gathered}
F_{T}=\varepsilon(1-\mu \zeta) w d+F_{V} \\
\mu=\tan \phi \\
E=E_{o}+\mu S \\
E=\frac{F_{T}}{w d} \\
S=\frac{F_{V}}{w d}
\end{gathered}
$$

$$
E_{o}=\varepsilon(1-\mu \zeta)
$$

The feasibility of RSD to estimate rock strength parameters from scratching test was first conducted in [54]. The researchers used blunt and sharp cutters in conducting the scratch tests on sandstone samples. The RSD was utilized [46] to investigate to estimate the rock strength of different rocks using scratch test method. The experiment was conducted on 130 quarry rocks and 236 oil and gas reservoir rocks (sandstones, limestones, dolomites and shales). The results of the tests show strong correlation between the values of intrinsic specific energy $(\varepsilon)$ and the UCS. Another study [52] on 35 different sandstone samples and 24 different carbonate samples was conducted to assess the strength and Young's modulus (stiffness) of sedimentary rocks through scratch testing. The values of intrinsic specific energy $(\varepsilon)$ obtained in their results agree with the UCS, which further validates the efficiency of scratch test for quick and effective estimation of UCS and other geomechanical properties in rocks.

Thin layer of weakness or heterogeneity along rock core can be captured through scratch testing, and this was showed [48] in the rock strength estimation experiment conducted using the RSD. The UCS results [66] from the uniaxial lab test and the scratch test from Brazilian limestone core with high heterogeneity was presented by researchers. Their results validated the use of scratch testing to estimate UCS and Young's modulus in rocks such as limestone.

Authors [67] combined the strength profiles with well logs to create correlations of strength and other petrophysical properties such as porosity, density, and sonic velocity. The continuous strength profile obtained provides a reliable quantitative measurement of the scale and distribution of the heterogenous properties along the tested core samples. The mechanistic basis of equivalence between a rock's estimated intrinsic specific energy $(\varepsilon)$ and the UCS was further validated by a research conducted using the scratch test. In the authors' results, they observed in sedimentary rocks that in addition to the compressive strength, the MohrCoulomb failure envelope could also be obtained by scratch testing by the substitution of the scratching tool or cutter in order to evaluate the rock friction coefficient. The UCS of carbonate rocks was estimated by conducting 85 uniaxial compressive tests with RSD, and the result range from 9.16 $\mathrm{MPa}$ to $401.83 \mathrm{MPa}$ [56]. The authors in [54] attempted to investigate the rock strength under the ductile-failure mode, and the $K_{I C}$ under the under brittle-failure mode through scratch testing method. The authors applied the Bažant's Size Effect Law (SEL) to the 
experimental results to estimate $K_{I C}$ and UCS of different rock types. The fracture toughness values are estimated in brittle regime, while the UCS is estimated in ductile regime.

Some researchers attempted to investigate the mechanical properties of 4 different rocks (limestone, coal, conglomerate, siltstone) using scratch tests with various scratch probes [68]. In their results, they observed high degree of agreement between the values average normal force and the compressive and tensile strengths of the rocks tested. They showed that the UCS and Brazilian tensile strength (BTS) of the 4 different rock samples can be estimated by averaging the forces acting on the cutter in the scratch test. The authors also suggested that the rock properties can be best estimated at cutter penetration depth $>0.4 \mathrm{~mm}$. The results from the study can be used for borehole probe design for evaluation of rock strength in small hole drilled for bolting or blasting.

The rock material and rock material strength have been mostly mis-interpreted to be equal to intact rock and intact rock strength [69]. This misconception was properly defined $[70,71]$ where intact rocks are rocks that are free from fractures and contains minimal disturbance by the core sampling process; whereas intact rock strength is the UCS of intact rock conducted in core samples of $\sim 0.2 \mathrm{ft}$ in diameter. The successive tests conducted [72] proposed that a rock's principal stresses relationship at failure are characterized by two parameters, the uniaxial compressive strength and an instant rock strength parameter. The author suggested those parameters could be estimated in rocks by unconfined compression test and the Brazilian indirect tension test.

\subsection{Fracture Toughness}

Fracture toughness $\left(K_{I C}\right)$ is a measure of a material's resistance to fracture propagation. Propagating fractures tends to travel along the path of lowest resistance, but the fracture orientation, direction and limit of its path creates a complex relationship between in-situ stress-field, the rock's anisotropic mechanical properties, and the pore pressure, and fracturing pressure [43]. Reliable geomechanical values such as $K_{I C}$, are of upmost importance in hydraulic fracturing design and simulation to achieve successful operation and optimum hydrocarbon recovery. Notwithstanding the several attempts by researchers to investigate the elastoplastic behavior of shale rocks, its fracture characterization has not been adequately investigated. It is a common knowledge that fractures is inherently a multi-scale phenomenon, but a substantial number of studies have limited fractures to the macroscopic sphere. The novel study by [31] was focused on fracture characterization in gas shales using the scratch test method. The authors used shale rocks from 3 systems: Torcian Shale in Paris, Basin, France, and Lower and Upper Woodford shale in Oklahoma, USA. The authors presented a novel method of estimating fracture energy and $K_{I C}$ in shale rocks at microscopic scale through the scratch testing method. An experiment involving four consecutive tests with an Anton Paar scratch testing machine was utilized for this study using a sphero-conical scratch probe.

The authors presented a scratch force linear relationship for scratch probes with axisymmetric shapes [11]. In the force-scaling relationship developed, the scratch probe geometries considered are conical probe, flat punch, and hemi-spherical probe. The scratch force criterion utilized for characterizing scratch resistance of materials is termed as the scratch hardness $\left(H_{T}\right)$ [75], and it can be quantified in Eqn. (5) as:

$$
F_{T} \stackrel{\text { def }}{=} H_{T} A_{C}
$$

The authors [74] addressed the limitation of study [6] in accounting for cutter blade width in estimation of $K_{I C}$. The force-scaling relationship for scratch probe geometries are well defined [7, 11] in Eqn. (6) for conical scratch probe, and in Eqn. (7) for spherical scratch probe:

$$
\begin{aligned}
& F_{e q}=\sqrt{{F_{T}}^{2}+\frac{3}{5}{F_{V}}^{2}} \\
& F_{e q}=\sqrt{{F_{T}}^{2}+\frac{665}{1188}{F_{V}}^{2}}
\end{aligned}
$$

For the crack-initiation point, authors in [31] used threshold criterion for the energy release rate $(\mathcal{G})$; that the fracture propagation occurs when $\mathcal{G}=$ $\mathcal{G}_{f}$. Where $\mathcal{G}_{f}$, is the fracture energy and is the threshold value. Their scratch fracture toughness $\left(\mathrm{K}_{S}\right)$ estimation is given as:

$$
K_{S}=\frac{F_{T}}{\sqrt{2 p A_{c}}}
$$

The scratch toughness of shale rock in Eqn. (1) is highly dependent on scratch orientation, while the probe function, $2 p A_{c}$ is dependent on the stylus geometry and the penetration depth, $d$. The term $2 p A_{c}$ is applicable for scratch testing using flat punch, spherical, and conical or sphero-conical scratch probe geometries. Since a sphero-conical probe was utilized, the expression for the probe function was given as:

$$
2 p A_{c}=\frac{4 \tan \theta}{\cos \theta d^{3}}
$$

The authors also attempted to estimate $\mathcal{G}_{f}$ for an anisotropic material such as shale rock, using the J- 
integral solution $[75,76]$. The fracture energy $\left(\mathcal{G}_{f}\right)$ for anisotropic rocks such as shale is given as:

$$
\mathcal{G}_{f}=\frac{1-v^{2} a b}{\mathrm{E}_{a}} K_{s}^{2}
$$

where $E_{a}$, is the Young's modulus parallel to the bedding plane, while $v_{a b}$, is the Poisson's ratio parallel to the bedding plane.

From their results, the authors observed that increase in penetration depth $\mathrm{d}$ yields higher fracture toughness $\left(\mathrm{K}_{S}\right)$ and focalize at an asymptotic value $\left(K_{S}{ }^{\infty}\right)$ which highlights the ductile-to-brittle transition as a function of depth of penetration. The microscopic scratch toughness estimated was observed to be to three times greater than the macroscopic fracture toughness estimated through other methods, while the microscopic fracture energy is twice as much as that estimated by other researchers at macroscopic scale. The scanning electron microscopy (SEM) result shows very rough scratch surfaces which tends to result in deflection of the fracture, due to the interaction between the shale rock's weaker component such as clay, and much stronger constituents such as quartz. The fracture mechanical behavior observed by the authors from the SEM images are: (i) particle pull-out; (ii) fracture bridging; and (iii) fracture branching, microfracturing, and fracture trapping.

In a microscale experimental study [77], fracture mechanical behavior was investigated to characterize its initiation and propagation in shale and sandstone rocks using microscale mechanical scratch tests.

The $K_{I C}$ and fracture directionality were evaluated in the formation to identify the effect of grain-scale heterogeneity and inelasticity on hydraulic fracturing design and operations. Microscratch testing was conducted on the shale and sandstone cores used in the experiment and the cores are sourced from the Monterey formation. The continuity of core scratching increases the degree of elastic and plastic deformation of the rock. In $F_{T}$ vs. scratch length results for sandstone and shale, the instantaneous change in penetration depth along the scratch length signifies fracture occurrences.

In cores oriented along the bedding plane in shale rocks, $K_{I C}$ values intersect at an average value with increase in scratch length, and this is similar to the asymptotic value $\left(K_{S}{ }^{\infty}\right)$ in [31]. The authors [77] combined Acoustic Emission (AE) with SEM to observe the scratch area, and the damage within and outside the scratch path, to characterize the crack surface events. The fracture mechanical behavior in sandstone and shale rock samples includes fracture branching, fracture bridging, particle pull-out, and fracture deflection. This validates the shale fracture mechanical behavior presented in [31].

\subsection{Other Parameters}

Scratch testing was utilized in sanding prediction evaluation by obtaining the vertical distribution of the rock's mechanical properties [60]. The logging measurements (GR, Sonic, porosity, and density) of the mechanical properties was obtained experimentally using the TerraTek $\mathrm{TSI}^{\mathrm{TM}}$ scratch machine. The tests conducted on $85 \mathrm{ft}$ sandstone reservoir provided reliable results showing the capability of the scratch testing to (i) evaluate the vertical heterogeneity of the core; (ii) choose a number that is representative of the core sections for rock mechanical experiments; (iii) displaying the minimum vertical resolution display and $\log$ evaluation; (iv) provide quick and immediate calibration of logs for proactive decision to prevent wellbore instability and sand production.

Micro-scratch test can be resourceful in evaluating mudrock brittleness of shale rocks [78]. The results showed that the transverse force measured can be used to estimate rock brittleness index. The impact of scratching speed, loading rate and diamond probe radius on the critical load for scratch tests was conducted on coatings of diamond indenter [24]. Scratch testing also proved resourceful in studying the effect of bit wear in polycrystalline diamond compact (PDC) bits [79]. UCS from scratch test can be combined with sedimentology, core analysis and wireline logs to provide better characterization of rock's heterogeneity and create continuous profile of the geomechnical properties in un-cored intervals [80].

Borehole instability issues arising from oil and gas drilling operations can addressed by predicting the strength of homogenous and heterogenous rocks using scratch test [63]. This test was conducted on 13 carbonate and sandstone rocks with the scratching cell. Researchers [61] utilized the scratch testing method to evaluate continuous rock drillability by correlating the scratch test's intrinsic specific energy and the micro-drilling tests with PDC bits. In their results, the drillability of heterogenous sandstone from Songnan oilfield, China, was determined using combination of scratch and micro-drill tests. Filter cakes formed by various mud systems was addressed using scratch test method to determine the rock strength and stiffness and correlated them to external filter cake probing. In the research results [81] conducted on sandstone samples, the scratch test tool showed the entire shear strength profile starting from the mud/cake interface to the cake/rock boundary. The authors also showed the capability of the scratch testing tool to clean-out mud filter cake layers to a lowly thickness of $0.1 \mathrm{~mm}$. 


\section{Conclusions and recommendations}

In this paper, we provided an up-to-date review the use of scratch testing method to estimate rock strength and other geomechanical properties over the past few decades. Subsequently, we presented the comparison of scratch testing method to other conventional methods. We further highlighted the methodology, modifications, and applications of the scratch test and its devices published research studies. The advantages of scratch test method over other conventional methods in estimating rock strength and other geomechanical properties are that:

a. It is quasi non-destructive, and the post-test core samples remain intact which can be utilized for other destructive or non-destructive tests.

b. It provides direct equivalent measurement with the rock's UCS.

c. It requires limited and minimal level of sample preparation.

d. It is simple, quick, and highly repeatable.

e. It can be conducted on any dimension of rock, as the results are not affected by the core sample geometry.

f. It provides precise continuous profile of rock strength over the scratch interval.

In our statistical analysis of papers reviewed, the scratch test utilization for estimating rock strength is $56 \%$, other parameters is $33 \%$, and fracture toughness is $11 \%$. This shows there is minimal study on fracture toughness estimation in rocks using scratch test method.

Based on outstanding issues for studies of UCS, $K_{I C}$, and other geomechanical properties, we propose the following recommendations for further research to improve optimization of hydrocarbon exploitation, energy storage, and field-scale modeling for energy production operations.:

a. Extended study of rock fracture characterization at a microscopic scale.

b. Further study on the heterogenous microstructure and composition of rocks with a high-level accuracy.

c. Achieving a rock surface roughness with a lower maximum penetration depth over an extended surface area.

\section{References}

1. M. Wigwe, O. Kolawole, M. Watson, I. Ispas, W. Li. Influence of Fracture Treatment Parameters on Hydraulic Fracturing Optimization in Unconventional Formations. American Rock Mechanics Association, ARMA-CUPB-19-3666 (2019).
2. O. Kolawole, S. Esmaeilpour, R. Hunky, L. Saleh, H.K. Ali-Alhaj, M. Marghani. Optimization of Hydraulic Fracturing Design in Unconventional Formations: Impact of Treatment Parameters. Society of Petroleum Engineers (2019). https://doi.org/10.2118/198031-MS.

3. O. Kolawole, I. Ispas. Interaction between hydraulic fractures and natural fractures: current status and prospective directions. Journal of Petroleum Exploration and Production Technology, 10:16131634 (2020). https://doi.org/10.1007/s13202-01900778-3.

4. O. Kolawole, I. Ispas. How Hydraulic Fractures Interact with Natural Fractures: A Review and New Observations. American Rock Mechanics Association, ARMA-2019-0018 (2019).

5. M. Thiercelin, R.G. Jeffrey, K.B. Naceur. Influence of Fracture Toughness on the Geometry of Hydraulic Fractures. Society of Petroleum Engineers (1989). https://doi.org/10.2118/16431-PA.

6. A.-T. Akono, F.-J. Ulm. Scratch test model for the determination of fracture toughness. Engineering Fracture Mechanics, 78:334-342 (2011). https://doi.org/10.1016/j.engfracmech.2010.09.017.

7. J.-S. Lin, Y. Zhou. Can scratch tests give fracture toughness? Engineering Fracture Mechanics, 109:161-168 (2013). https://doi.org/10.1016/j.engfracmech.2013.06.002.

8. J.-L. Le, E. Detournay. Discussion on the "Fracture mechanics interpretation of the scratch test" by Akono et al. Engineering Fracture Mechanics, 168(A):46-50 (2016). https://doi.org/10.1016/j.engfracmech.2016.09.010.

9. S. $\mathrm{Al}$ Wakeel, M.H. Hubler. Introducing Heterogeneity into the Micro-Scratch Test Fracture Toughness Relation for Brittle Particle Composites. Exp Mech, 58: 1237 (2018). https://doi.org/10.1007/s11340-018-0408-1.

10. G.R. Anstis, P. Chantikul, B.R. Lawn, D.B. Marshall. A critical evaluation of indentation techniques for measuring fracture toughness: I, direct crack measurements. J Am Ceram Soc, 64(9):533-538 (1981). https://doi.org/10.1111/j.11512916.1981.tb10320.x.

11. I. Larsen, L. Li, R.M. Holt. Estimation of Intergranular Bond Strengths by Core Scratching: A Comparison Between A Laboratory Experiment and A Numerical Discrete Particle Simulation. American Rock Mechanics Association (2004).

12. F.-J. Ulm, S. James. The scratch test for strength and fracture toughness determination of oil well cements cured at high temperature and pressure. Cement and Concrete Research, 41(9):942-946 (2011). https://doi.org/10.1016/j.cemconres.2011.04.014.

13. A.-T. Akono, N.F. Randall, F.-J. Ulm. Experimental determination of the fracture toughness via microscratch tests: Application to polymers, ceramics, and metals. Journal of Materials Research, 27(2):485493 (2012). https://doi.org/10.1557/jmr.2011.402.

14. R. Sola, R. Giovanardi, G. Parigi, P.A. Veronesi. Novel Methods for Fracture Toughness Evaluation of Tool Steels with Post-Tempering Cryogenic 
Treatment. Metals, 7: $75 \quad$ (2017). https://doi.org/10.3390/met7030075.

15. F. Pöhl, S. Schwarz, P. Junker, K. Hackl, W. Theisen. Indentation and scratch testing - experiment and simulation. International Conference on Stone and Concrete Machining (ICSCM), 3:292-308 (2015). https://doi.org/10.13154/icscm.3.2015.292-308.

16. D. Beegan, S. Chowdhury, M.T. Laugier. Comparison between nanoindentation and scratch test hardness (scratch hardness) values of copper thin films on oxidised silicon substrates. Surf. Coat. Technol., 201:5804-5808 (2007).

17. V. Jardret, H. Zahouani, J.L. Loubet, T.G. Mathia. Understanding and quantification of elastic and plastic deformation during a scratch test. Wear, 218:8-14 (1998). https://doi.org/10.1016/S0043-1648(98)002002.

18. E. Felder, J.L. Bucaille. Chapter 2 Mechanical analysis of the scratching of metals and polymers at moderate and large strains. Tribol. Interface. Eng. Ser., 51:22-55 (2006). https://doi.org/10.1016/S01678922(06)80038-6.

19. O. Borrero-López, M. Hoffman, A. Bendavid, P.J. Martin. The use of the scratch test to measure the fracture strength of brittle thin films. Thin Solid Films, 518:4911-4917 (2010).

20. R. Lach, L.A. Gyurova, W. Grellmann. Application of indentation fracture mechanics approach for determination of fracture toughness of brittle polymer systems. Polym Test, 26(1):51-59 (2007). https://doi.org/10.1016/j.polymertesting.2006.08.006.

21. W. Brostow, W. Chonkaew, R. Mirshams, A. Srivastava. Characterization of grooves in scratch resistance testing. Polym. Eng. Sci., 48:2060-2065 (2008). https://doi.org/10.1002/pen.21085.

22. A.-T. Akono, F.-J. Ulm. An improved technique for characterizing the fracture toughness via scratch test experiments. Wear, 313:117-124 (2014). https://doi.org/10.1016/j.engfracmech.2010.09.017.

23. W. Brostow, W. Chonkaew, L. Rapoport, Y. Soifer, A. Verdyan. Grooves in scratch testing. J. Mater. Res., 22:2483-2487 https://doi.org/10.1557/jmr.2007.0307.

(2007).

24. M.M. Hossain, R. Minkwitz, P. Charoensirisomboon, H.-J. Sue. Quantitative modeling of scratch-induced deformation in amorphous polymers. Polymer, 55 (23):6152-6166 (2014).

25. N.X. Randall, G. Favaro, C.H. Frankel. The effect of intrinsic parameters on the critical load as measured with the scratch test method. Surf Coat Technol, 137:146-151 (2001). https://doi.org/10.1016/S02578972(00)01097-5.

26. D. Martogi, S. Abedi, S. Crystal, I. Mitchell. Mechanical Properties of Drill Cuttings Based on Indentation Testing and Contact Mechanics Solutions. Society of Petroleum Engineers (2019). https://doi.org/10.2118/196214-MS.

27. K. Liu, M. Ostadhassan, B. Bubach. Applications of nano-indentation methods to estimate nanoscale mechanical properties of shale reservoir rocks. J. Nat. Gas Sci. Eng., 35(A):1310-1319. https://doi.org/10.1016/j.jngse.2016.09.068.
28. Q. Zeng, Y. Feng, S. Xu. A discussion of "Application of nano-indentation methods to estimate nanoscale mechanical properties of shale reservoir rocks" by K Liu, M Osatadhassan and B Bubach. J. Nat. Gas Sci. $\begin{array}{llll}\text { Eng. } & 42 & 187-189 & \text { (2017). }\end{array}$ https://doi.org/10.1016/j.jngse.2017.02.027.

29. P. Chen, Q. Han, T. Ma, D. Lin. The mechanical properties of shale based on micro-indentation test. PETROL. EXPLOR. DEVELOP., 42(5):723-732 (2015). https://doi.org/10.1016/S1876-3804(15)300690.

30. X. Su, P. Chen, T. Ma. Evaluation of shale fracture toughness based on micrometer indentation test. Petroleum, 5(1):52-57 (2018). https://doi.org/10.1016/j.petlm.2018.05.005.

31. A.-T. Akono, P. Kabir. Microscopic fracture characterization of gas shale via scratch testing. Mechanics Research Communications, 78:86-92 (2016). https://doi.org/10.1016/j.mechrescom.2015.12.003.

32. E. Broch, J.A. Franklin. Point-Load Strength Test. International J. Rock Mechanics \& Mining Sci., 9(6):669-676 (1972). http://dx.doi.org/10.1016/01489062(72)90030-7.

33. Z.T. Bieniawski. The Point Load Test in Geotechnical Practice. Eng. Geology, 9:1-11 (1975). http://dx.doi.org/10.1016/0013-7952(75)90024-1.

34. J.S. Lee, J. Kieschnick, C. Geyer, J. Brumley, L. DeSpain. Comparison of Different Methods to Estimate Uniaxial Compressive Strength in a Barnett Shale. American Rock Mechanics Association (2016).

35. Papworths Construction Testing Equipment (PCTE), Equotip 3 - Non-destructive test for rock UCS. Equotip-3 for Rock Brochure 1-2.

36. W. Verwall, \& A. Mulder, Rock and aggregate laboratory manual, 13-14. Geotechnical Laboratory DGM, Thimphu Bhutan (2000).

37. J.S. Lee. Calibration of rebound hardness numbers to UCS in shale formations. J. Petrol. Tech., 67(1):41-45 (2015). https://doi.org/10.2118/0115-0041-JPT.

38. J.S. Lee, L. Smallwood, E. Morgan. New Application of Rebound Hardness Numbers to Generate Logging of Unconfined Compressive Strength in Laminated Shale Formations. American Rock Mechanics Association (2014).

39. A. Aydin, A. Basu. The Schmidt Hammer in Rock Material Characterization. Eng. Geology, 81(1):1-14 (2005). http://dx.doi.org/10.1016/j.enggeo.2005.06.006.

40. C. Germay, T. Richard. The Scratch Test: A High Resolution Log of Rock Strength with Application to Geomechanic and Petrophysic. Society of Petrophysicists and Well-Log Analysts (2014).

41. D. Gokaraju, S. Govindarajan, A. Mitra, M. Aldin, R. Patterson. Evaluation of Fracture Toughness and Its Impact on Hydraulic Fracturing. American Rock Mechanics Association, (2017).

42. R. Sierra, M. H. Tran, Y. N. Abousleiman, R. M. Slatt. Woodford Shale Mechanical Properties and the Impacts of Lithofacies. American Rock Mechanics Association (2010). 
43. M. Chandler, P. Meredith, B. Crawford. Experimental determination of the fracture toughness the Mancos shale, Utah. Geophys. Res. Abstr., 15, EGU2013-1331 (2013). https://doi.org/10.3997/2214-4609.20130286.

44. D. Moronkeji, R. Villegas, R. Shouse, U. Prasad. Rock strength prediction during coring operation. In Proc. of International Symposium of the Society of Core Analysts, SCA2017-048 (2017).

45. F. Dagrain, C. Germay. Fields applications for the scratching tests. In Proc. of the Eurock 2006: Multiphysics Coupling and Long Term Behaviour in Rock Mechanics, 571-576 (2006).

46. T. Richard, F. Dagrain, E. Poyol, E. Detournay. Rock strength determination from scratch tests. Eng. Geol., 147-148:91-100

(2012). https://doi.org/10.1016/j.enggeo.2012.07.011.

47. F. Dagrain, T. Richard, C. Germay. The Rock Strength Device : A scratching apparatus to determine rock properties. The 7th National Congress on theoretical and applied Mechanics NCTAM (2006).

48. S. Mitaim, F. Dagrain, T. Richard, E. Detournay, A. Drescher. A novel apparatus to determine the rock strength parameters. In Proc. of the 9th National Convention on Civil Engineering, Thailand (2004).

49. C. Coudyzer, E. Poyol, P. Bette, F. Dagrain. Measure of rock mechanical properties from scratching test. AAPG International Conferences and Exhibition (2005).

50. C. Germay, T. Richard, E. Mappanyompa, C. Lindsay, D. Kitching, A. Khaksar. The Continuous-Scratch Profile: A High-Resolution Strength Log for Geomechanical and Petrophysical Characterization of Rocks. Society of Petroleum Engineers (2015). https://doi.org/10.2118/174086-PA.

51. C. Germay, T. Lhomme, C. McPhee, G. Daniels. An Objective Review of Non-Destructive Methods for the Direct Testing of Strength on Rock Cores. American Rock Mechanics Association (2018).

52. G. Schei, E. Fjær, E. Detournay, C.J. Kenter, G.F. Fuh, F. Zausa. The Scratch Test: An Attractive Technique for Determining Strength and Elastic Properties of Sedimentary Rocks. Society of Petroleum Engineers (2000). https://doi.org/10.2118/63255-MS.

53. X. He, C. Xu. Determining Strength and Fracture Toughness of Rock from Scratch Tests. International Society for Rock Mechanics and Rock Engineering (2015).

54. J.I. Adachi, E. Detournay, A. Drescher. Determination of Rock Strength Parameters from Cutting Tests. American Rock Mechanics Association (1996).

55. E. Detournay, A. Drescher, and D.A. Hultman. United States Patent 5670711 (1997).

56. J.I. Adachi, Detournay E., Drescher A. Determination of rock strength parameters from cutting tests, rock mechanics tools and techniques. In Proc. of 2nd North American Rock Mechanics Symposium (NARMS 1996), Montreal, 1517-1523 (1996).

57. C. Germay, C. Coudyzer, E. Poyol, F. Dagrain. Measure of rock mechanical properties from cutting test. McMat 2005 Mechanics \& Materials conference, June 1-3, Baton Rouge, Louisiana, USA (2005).
58. F. Dagrain, E. Poyol, T. Richard. Strength Logging of Geomaterials from Scratch Tests. In Schubert (ed.) Proceedings of ISRM Regional Symposium EUROCK 2004 and 53rd Geomechanics Colloquium (2004).

59. Epslog S.A. Wombat Machine, The Wombat Automated Apparatus and Software (2019).

60. R. Suarez-Rivera, J. Stenebråten, F. Dagrain. Continuous scratch testing on core allows effective calibration of log-derived mechanical properties for use in sanding prediction evaluation. Society of Petroleum Engineers (2002). https://doi.org/10.2118/78157-MS.

61. J. Chen, Y. Feng, Y. Zeng, Y. Han, Y. Wang, C. Niu. Continuous rock drillability measurements using scratch tests. Journal of Petroleum Science and Engineering, $\quad 159: 783-790 \quad$ (2017). https://doi.org/10.1016/j.petrol.2017.08.030.

62. TerraTek Mechanical Properties Profile Service. Schlumberger (2014).

63. I. Ali, M.N.J. Al Awad. Applications of Rock Scratching Tests in Borehole Instability. American Rock Mechanics Association (2014).

64. A. Naeimipour, J. Rostami, I.S. Buyuksagis, O. Frough. Estimation of rock strength using scratch test by a miniature disc cutter on rock cores or inside boreholes. Int J Rock Mech Min Sci, 10:9-18 (2018).

65. E. Detournay, P. Defourny. A phenomenological model for the drilling action of drag bits. International Journal of Rock Mechanics and Mining Sciences and Geomechanics Abstracts 29 (1) 13-23 (1992). https://doi.org/10.1016/0148-9062(92)91041-3.

66. F.H. Ferreira, C. Germay, E.S.R. Santos, D.F. Rossi. From Lab to Field: Rock Mechanics Properties Assessment for a 3D MEM. American Rock Mechanics Association (2017).

67. C. Fairhurst. The Scratch Test - An Innovative and Inexpensive Method to Determine the Compressive Strength and Mohr-Coulomb Failure Envelope for Sedimentary Rock. International Society for Rock Mechanics and Rock Engineering (2014).

68. A. Naeimipour, J. Rostami, E. Keller, O. Frough, S. Wang. Estimation of Rock Strength by Means of Scratch Probe. American Rock Mechanics Association (2015).

69. A.J. Gonzalez-Garcia. Rock Strength and Failure: Some Common and Uncommon Issues. International Society for Rock Mechanics and Rock Engineering (2011).

70. E. Hoek, E.T. Brown. Brown Underground excavations in rock. London: Instn Min. Metall. (1980).

71. E. Hoek, E.T. Brown. Empirical strength criterion for rock masses. Journal Geotechnical Engineering Division, ASCE 106(GT9):1013-1035 (1980).

72. E. Hoek, Practical Rock Engineering - An Ongoing Set of Notes (2007).

73. J.A. Williams. Analytical models of scratch hardness. Tribol. Int., 29 (8) 675-694 (1996).

74. A.-T. Akono, F.-J. Ulm, Z.P. Bažant. Discussion: Strength-to-fracture scaling in scratching. Engineering Fracture Mechanics, 119 21-28 (2014). https://doi.org/10.1016/j.engfracmech.2014.02.025. 
75. H.H. Laubie. Linear Elastic Fracture Mechanics in Anisotropic Solids: Application to Fluid-Driven Crack Propagation. Master thesis, Massachusetts Institute of Technology (2013).

76. H. Laubie, F.-J. Ulm. Plane-strain crack problem in transversely isotropic solids for hydraulic fracturing applications. J. Eng. Mech., 140(12):04014092 (2014). http://ascelibrary.org/doi/full/10.1061/(ASCE)EM.194 3-7889.0000807.

77. M. A. Ante, G. L. Manjunath, F. Aminzadeh, B. Jha. Microscale Laboratory Studies for Determining Fracture Directionality in Tight Sandstone and Shale During Hydraulic Fracturing. Unconventional Resources Technology Conference (2018). https://doi.org/10.15530/URTEC-2018-2903021.

78. L.A. Hernandez-Uribe, M. Aman, D.N. Espinoza. Assessment of Mudrock Brittleness with Microscratch Testing. Rock Mech Rock Eng., 50:2849 (2017). https://doi.org/10.1007/s00603-017-1279-y.

79. I.H. Michaels, M. Mostofi, T. Richard. An Experimental Study of the Wear of Polycrystalline Diamond Compact Bits. American Rock Mechanics Association (2019).

80. M.T. Nguyen, T. Worku, W.P. Mitchell, M.R. Lakshmikantha, M. Hegazy. An Integrated Approach Using Geomechanics and Advanced Rock Characterization Technics to Optimize Reservoir Productivity and Stimulation Design. Society of Petroleum Engineers (2014). https://doi.org/10.2118/169915-MS.

81. P. Cerasi, I. Larsen, J.F. Stenebråten, E.F. Sonstebo. Scratch testing of drilling mud filter cakes. Society of Petroleum Engineers (2006). https://doi.org/10.2118/100130-MS. 